\title{
A hispanidade reivindicada: Pinochet e a apropriação do franquismo no Chile (1973-1975)
}

André Mateus Pupin ${ }^{1}$

\begin{abstract}
Resumo: O objetivo do artigo é explicar e analisar as apropriações culturais e ideológicas que a ditadura de Augusto Pinochet estabeleceu em relação ao regime autoritário de Francisco Franco. O franquismo criou, em 1948, o Instituto de Cultura Hispânica, o Instituto Chileno de Cultura Hispânica e a revista Cuadernos Hispanoamericanos, por meio dos quais buscou reforçar um imaginário hispano-americano que enaltecia os valores e a cultura da antiga Metrópole. Por sua vez, a ditadura pinochetista promoveu elementos desse repertório, apropriando-se dos valores conservadores da hispanidade para justificar ações culturais e políticas durante sua permanência no poder. A releitura pinochetista sobre os legados da herança espanhola legitimaram a estratégia do ditador sul-americano em seu discurso de combate ao comunismo e à secularização, apontados como causa da decadência da tradição hispânica.
\end{abstract}

Palavras-chave: Pinochetismo; Franquismo; Projetos culturais.

\section{The claimed hispanity: Pinochet and the appropriation of Francoism in Chile (1973-1975)}

\begin{abstract}
The objective of the article is to explain and analyze the cultural and ideological appropriations established by Augusto Pinochet's dictatorship regarding Francisco Franco's authoritarian regime. Franco created, in 1948, the Institute of Hispanic Culture as well as its Chilean branch and the Cuadernos Hispanoamericanos magazine, strategies that sought to reinforce and connect a Hispanic American imaginary that praised the values and culture of the old Metropolis. On the other hand, Pinochet's dictatorship promoted elements of this repertoire by using the conservative values of hispanidad to justify cultural and political actions during its regime. The pinochetist appropriations of Spanish's legacies legitimized the strategy of the South American dictator in his discourse of combating communism and secularization, which was suggested to be the cause of Hispanic traditions decay.
\end{abstract}

Keywords: Pinochetism; Francoism; Cultural projects.

\footnotetext{
${ }^{1}$ Bacharel e licenciado em História pelo Instituto de Filosofia e Ciências Humanas da Universidade Estadual de Campinas (IFCH/UNICAMP). Mestrando em História na mesma instituição, onde desenvolve o projeto de pesquisa "Pontes de papel: intelectuais e concepções americanistas nos Cuadernos Americanos (1942-1959”, sob orientação do Prof. Dr. José Alves de Freitas Neto e com financiamento da Fundação de Amparo à Pesquisa do Estado de São Paulo - FAPESP (Processo $n^{\circ}$ 19/26616-4). A pesquisa que resultou no presente artigo também foi financiada pela FAPESP (Processos nº 17/25373-5 e n 18/20881-5). Contato: andrepupinrp@ hotmail.com
} 
Artigo recebido em: 30/06/2020

Artigo aprovado para publicação em: 04/09/2020

A ditadura chilena é conhecida pelo seu autoritarismo político e adoção de programas econômicos e sociais neoliberais. No plano cultural, houve iniciativas que constituíram uma terceira frente de legitimação, a partir de práticas como a apropriação do discurso franquista sobre a América Latina. O governo de Augusto Pinochet (1973-1990) construiu um discurso político-cultural que emulava as construções culturais da ditadura de Francisco Franco (19391975) e seus esforços em enaltecer e justificar seu poder a partir de memórias monumentalizadas da história da Espanha.

O objetivo deste artigo é analisar a apropriação pinochetista do franquismo na releitura do passado e da cultura hispânica e, devido às inter-relações, abordar as proposições franquistas sobre a América Latina. A ideia de um discurso homogeneizante sobre a cultura hispânica, centrada no catolicismo, gerou o enaltecimento de um efeito histórico liderado pelos espanhóis que reconfigurou a história global, como a conquista da América. Processos complexos que, em ambos os regimes, são apresentados sob uma ótica civilizadora e de fortalecimento de identidades. O imbricamento entre catolicismo e conquista do Novo Mundo é um fenômeno que permite leituras múltiplas sobre o legado hispânico para as sociedades americanas, mas na leitura de Pinochet emerge como uma blindagem à presença de discursos laicizantes ou de princípios que remetessem às disputas ocorridas na Guerra Civil Espanhola, como o republicanismo e o socialismo. A especificidade da leitura de Pinochet em relação ao modelo cultural franquista, por exemplo, permite destacar certo distanciamento e crítica ao rei Juan Carlos I, fruto do processo de transição para a democracia, por sua suposta ingratidão ao legado de Franco. Assim, as políticas culturais pinochetista e franquista utilizaram o passado colonial espanhol como forma de apagamento das contradições e violações de seus regimes.

Tais questões foram analisadas a partir de três fontes: o jornal chileno El Mercurio, o jornal espanhol $A B C$ e a revista Cuadernos Hispanoamericanos $(\mathrm{CH})$. O jornal chileno $E l$ Mercurio foi fundado em 1827, na cidade de Valparaíso, durante a primeira década do Chile independente, e, em 1900, na capital do país - Santiago. Desde 1854 pertence à família Edwards, compondo a maior empresa jornalística do Chile, com vinte diários regionais e três nacionais. 
Cabe apontar que El Mercurio não foi apenas um jornal conservador durante a ditadura de Augusto Pinochet (1973-1990), mas também um guardião do pinochetismo e um dos propagadores do negacionismo em relação à tortura, aos desaparecimento e às mortes causados pelo regime. Desde sua fundação, em 1905, o jornal espanhol ABC foi conservador e monarquista, a ponto do seu fundador receber o título de marquês, em 1929, do rei Alfonso XIII. Sua relação com o franquismo intensificou-se no final da ditadura, em 1967, quando seu diretor Torcuato Luca de Tena y Brunet foi nomeado, por Franco, procurador nas Cortes espanholas que, formalmente, funcionavam como Parlamento durante o franquismo (RODRÍGUEZMARTÍNEZ; TULLOCH; LLOVERAS, 2017, p. 605). Já a revista Cuadernos Hispanoamericanos (CH), fundada em 1948, em Madrid, foi uma importante iniciativa do projeto cultural e editorial franquista. Era responsável por difundir a noção de hispanidade, que defendia uma América Hispânica unida graças ao legado espanhol, sobretudo língua castelhana e religião católica.

Assim, debruçaremo-nos sobre as apropriações pinochetistas por meio de recortes do jornal chileno El Mercurio e do jornal espanhol $A B C$, buscando compreender quais tipos de apropriações foram feitas, suas motivações e consequências, especificamente a partir das publicações sobre a ida de Pinochet ao funeral de Franco (novembro de 1975) e das comemorações do Dia da Hispanidade (12 de outubro de 1975).

\section{Pinochet e Franco: usos do passado intermediados pela imprensa}

O uso político do passado não é uma novidade, afinal, a história possui, por definição, uma atividade política (LEVI, 2001, p. 26). O tema clássico está presente desde as origens da história, por exemplo, com os usos do passado antigo e medieval na formação das nações europeias. Todavia, o uso do passado recente foi intensificado a partir dos anos 1970 e 1980, com a virada da história contemporânea e do tempo presente (HARTOG e REVEL, 2001, p. 2021). Também no final do século $X X$, no caso do Cone Sul, houve uma organização de intelectuais em torno dos discursos de direitos humanos (RONIGER e KIERSZENBAUM, 2005), de forma que o passado que não passa ganhou espaço na historiografia, e as memórias reprimidas por ditaduras foram paulatinamente ganhando espaço na forma de estudos históricos complexos. 
Dentro dessas complexidades, o estudo do pensamento conservador pinochetista e franquista revela que as rememorações e comemorações das glórias do passado colonial espanhol buscavam, na verdade, retirar a atenção das violações políticas e aos direitos humanos que seus governos cometiam. É nesse sentido que utilizam a hispanidade como "cortina de fumaça", em mais uma substituição da história pelo mito, de fabricação de mentiras cometida por regimes autoritários (FINCHELSTEIN, 2020). Assim, interpretamos a apropriação pinochetista do franquismo como uma dupla clivagem de usos do passado através da hispanidade.

Nesse sentido, o marco metodológico em que nos situamos é o da História Intelectual Global, já que analisaremos uma revista cultural e dois jornais inseridos transnacionalmente e, sobretudo, a partir de uma problemática de usos políticos do passado que extrapolam fronteiras nacionais. Isso se aplica porque a História Intelectual é definida por Myers como um campo com fronteiras permeáveis no qual várias disciplinas e abordagens podem entrecruzar-se (2016, p. 23) Seu campo mais consolidado desde o seu início na América Latina, na década de 1980, são as revistas culturais; no entanto, também nesse ponto sua porosidade se manifesta em outras fontes, como jornais, centrais para o debate dentro do campo.

Os jornais revelam-se como uma fonte importante, sobretudo em sociedades sob ditaduras, nas quais esses veículos assumiram privilegiada importância como estratégias de comunicação. Evidentemente que as circunstâncias que permitiram a circulação dos jornais que analisaremos são particulares, na medida em que foram defensores do regime autoritário. Mesmo assim, cumpriram um papel, o qual deixou vestígios que demandam pesquisas.

\section{Hispanoamérica, um objetivo franquista}

O uso da hispanidade para uma chilenidade pinochetista não foi uma empreitada sem precedentes, pois Franco já tentara uma projeção no continente americano, principalmente durante o primeiro franquismo (1939-1959). Naquele período, a Espanha franquista encontravase isolada no cenário político mundial devido à aliança que fizera com os nazistas e fascistas na Guerra Civil Espanhola (1936-1939), conflito que também empobrecera o país. 
Além da decadência política e econômica, o governo do ditador espanhol era alvo de críticas de intelectuais, sendo um local privilegiado dessas produções o México, país que, acompanhado da União Soviética, do Chile e das Brigadas Internacionais, apoiou os republicanos durante o conflito interno. A partir de 1939, o país recebeu republicanos espanhóis exilados, com grande presença de intelectuais, os quais em 1942 contribuíram com a fundação da revista Cuadernos Americanos.

Com o objetivo de exercer influência sobre a América Latina e combater a propaganda negativa veiculada pelos espanhóis exilados, Franco criou a revista Cuadernos Hispanoamericanos, em 1948, publicada bimestralmente em formato de livro. Desde o início, a revista ficou vinculada ao Ministério de Relações Exteriores ${ }^{2}$, mais especificamente ao Instituto de Cultura Hispânica $(\mathrm{ICH})^{3}$, também sediado em Madri e com filiais em Lima, no Peru, e em Santiago do Chile.

Os $\mathrm{CH}^{4}$ e o $I C H$, de forma geral, possuíam como objetivo a divulgação da noção franquista de hispanidade. O conceito inicial, hispanismo, foi uma criação do século XIX após as independências das colônias americanas e procurava alimentar uma identidade comum entre Espanha e suas ex-colônias, elegendo a antiga metrópole como "pátria mãe” (BEIRED, 2006). Segundo Diffie $(1943)^{5}$, as origens da hispanidade encontram-se com a Falange, portanto, com o fascismo, distinguindo-se do hispanismo, ou pan-hispanismo, que, segundo o autor seria herdeiro de uma tradição iluminista. De qualquer forma, ambos possuem em comum um

\footnotetext{
${ }^{2}$ Importante observar que o controle da revista por um órgão responsável pelas relações internacionais do país revela o interesse sobre a América Latina para além do plano cultural. Com a Espanha aceita na União Europeia apenas em 1986, após o fim do franquismo (1975), havia a intenção de criar um Mercado Comum Ibero-Americano, projeto negligenciado com a entrada do país na Organização das Nações Unidas (ONU), em 1955.

3 ICH foi criado em 1945, substituindo o Consejo de Hispanidad que funcionava desde 1940. Tamanho foi o papel do ICH na política cultural franquista que, após o fim da ditadura e início do processo de redemocratização, teve novamente seu nome alterado para Instituto de Cooperação Ibero-americana, no início dos anos 1980 (MARTINS, 2012, p. 18).

4Cuadernos Hispanoamericanos foi inicialmente dirigida pelo espanhol Pedro Laín Entralgo e codirigida pelo argentino Mario Amadeo, sendo substituído pelo espanhol Luis Rosales em 1950. Além dessa revista, o ICH também editava outro periódico - Mundo Hispánico. Sobre a relação e disputa cultural entre Cuadernos Americanos e Cuadernos Hispanoamericanos, consultar a tese de Maria Antonia Dias Martins (2012).

$5 \mathrm{O}$ texto, aparentemente muito datado, enriquece nossa leitura pelo seu aspecto não apenas historiográfico mas também documental, uma vez que foi escrito enquanto essa mudança conceitual era operacionalizada - no caso, pelo precursor do ICH, o Consejo de Hispanidad.
} 
americanismo em prol do projeto nacional espanhol, ou seja, como parte de um "nacionalismo frustrado" (MARCILHACY, 2017, p. 80).

Ao explicarmos a hispanidade franquista, é necessário compreendermos o lugar da Falange nessa mudança conceitual. O fascismo espanhol, embora não tenha sido um movimento intelectual, foi proveniente de criações intelectuais no período das vanguardas artísticas. A Falange foi gestada na "corte literária" de José Antônio Primo de Rivera, tendo sido lançada em um teatro, o Teatro de Comédia de Madrid, em outubro de 1933 (GRECCO, 2017, p. 134-136).

Segundo Grecco (2017, p. 134), uma das redes intelectuais que forjou a Falange foi a Geração de 98, fruto da derrota espanhola na Guerra Hispano-Americana (1898), que acarretou a perda de mais colônias. Destaca-se nesse grupo Ramiro de Maeztu6 ${ }^{6}$ que publicou, em 1934, o livro Defensa de la Hispanidad, inaugurando o vocábulo. Seu uso pela Falange aglutinaria outros elementos presentes na retórica do grupo fascista, como o nacional-catolicismo e o apelo a mitos e figuras tradicionais, com destaque para Cristóvão Colombo e Isabel de Castela (ZORRILLA, 2014, p. 182).

Dessa forma, a nova palavra inaugurada por Maeztu e fascistizada com ajuda da Falange ocupou importante lugar no imaginário político conservador durante a Segunda República Espanhola, a Guerra Civil, e, sobretudo, o franquismo.

\section{IchCH: a filial chilena}

O Instituto Chileno de Cultura Hispânica (IchCH) foi fundado em 1948, três anos após a fundação do ICH, como parte do esforço diplomático do primeiro franquismo (1939-1959) sobre a América Hispânica. Mesmo antes da fundação do instituto, na década de 1930, já havia apoiadores do franquismo no Chile ${ }^{7}$, sobretudo na revista católica corporativista Estudios, com

\footnotetext{
6 Escritor e jornalista espanhol (1875-1936) foi um nacionalista que defendeu e justificou a Guerra Civil, a Falange e a ditadura franquista. Intelectual e embaixador na Argentina durante a ditadura de Miguel Primo de Rivera, fundou a revista e associação Acción Española, inspirando-se na Action Française, em 1931, e o partido Renovación Española, em 1933 (BEIRED, 2006, p. 6). Inclusive, Cuevas o coloca como equivalente a Carl Schmitt. Foi assassinado, em 1936, por milicianos republicanos (CUEVAS, 2003).

7 Não apenas apoiadores, como franquistas e falangistas exilados no Chile e em outros países da América, conforme aponta Luis Velasco Martínez no dossiê "Falangistas y franquistas en América" (2019). Nesse número especial da revista Historia 396, a historiadora Gabriela de Lima Grecco analisa o falangista espanhol Samuel Ros e seu exílio no Chile, entre 1937 e 1938.
} 
a presença de intelectuais como Osvaldo Lira ${ }^{8}$ e Jaime Eyzaguirre ${ }^{9}$ (HINOJOSA, 2008, p. 234). Tais intelectuais exerceram influência em gerações posteriores que vincularam-se à ditadura chilena, por exemplo, Jaime Guzmán ${ }^{10}$, intelectual articulador do pinochetismo, foi discípulo de Osvaldo Lira.

Nos seus trabalhos, a historiadora chilena Isabel Jara Hinojosa (2006 e 2008) investigou a relação cultural entre Espanha e Chile, contemplando desde 1936 até 1980. Entretanto, preocupou-se com as relações contemporâneas entre os países, de forma que a relação Franco e Pinochet se restringe aos primeiros anos do pinochetismo e dois últimos do franquismo (19731975). Neste artigo, diferentemente, procuramos investigar as apropriações culturais e ideológicas que o pinochetismo estabeleceu em relação ao primeiro franquismo (1939-1959), assunto que, embora apontado pela autora, não foi aprofundado por ela.

Outrossim, Hinojosa (2008, p. 234) aponta que o IchCH buscou consolidar o pensamento hispanista franquista no momento em que o Chile estava em processo de "esquerdização"11. Complementando, é interessante notar o Chile "direitizando-se", e usando o legado franquista, no momento que esse cenário era desmontado na Espanha em redemocratização, a qual buscava distanciar-se diplomaticamente do Chile governado por

8Osvaldo Lira (1998-1998) foi um padre e professor de filosofia chileno.

9Jaime Eyzaguirre (1908-1968) foi um advogado chileno ultra-católico. Professor da Faculdade de Direito da Universidade Católica desde 1932 e da Universidade do Chile desde 1953. Opositor ao pensamento liberal, buscou criticar essa corrente historiográfica com a historiografia hispanista, pela qual buscava defender a superação das atrocidades espanholas (leyenda negra) e também defendia a tradição hispânica como elemento da identidade nacional. Tinha a pretensão de publicar uma obra que abarcasse toda a história do Chile, mas morreu antes de concluí-la. Ver: Biblioteca Nacional de Chile. Jaime Eyzaguirre (1908-1968). Memória Chilena. Disponível em http://www.memoriachilena.gob.cl/602/w3-article-656.html\#bibliografia. Acesso em 18 de abril de 2020.

10Jaime Guzmán (1946-1991) admirava o corporativismo católico, sendo que através de Lira foi estimulado a ler sobre José Primo de Rivera e Francisco Franco. Também foi aluno do historiador hispanista Jaime Eyzaguirre e militou no grupo paramilitar de extrema-direita Frente Nacionalista Patria y Libertad entre 1970 e 1972 . Foi o responsável por escrever dois documentos centrais do pinochetismo: a Declaração de princípios da junta de governo militar do Chile (1974) e a Constituição de 1980, vigente até hoje no país.

11Importante destacar que o processo de "esquerdização" no Chile também esteve presente na década anterior, 1930, principalmente com o governo de Pedro Aguirre Cerda (1938-1941), que inclusive apoiou os republicanos na Guerra Civil Espanhola. Sobre isso, Mateus Fávaro Reis explica: "Durante os anos 30, Santiago renovou seu papel como polo de recepção de exilados oriundos de diversos países, a exemplo do que ocorrera em meados do século XIX. Se naquele século prevaleceram os argentinos, agora era a vez dos peruanos, em sua maioria apristas que fugiam de perseguições políticas. O Chile recebia, desse modo, um vasto contingente de personagens que desempenharam um importante papel para a consolidação de um amplo projeto editorial e que ajudou a renovar o lugar de Santiago como um dos mais importantes centros de circulação de intelectuais e políticos de toda a América Latina." (REIS, 2013, p. 3-4). 
Pinochet. Conforme destaca a autora, o Instituto sediado em Madri, o ICH, criticou abertamente a ditadura chilena:

El flanco que, sin embargo, la diplomacia chilena nunca pensó que tendría que defender, fue el del propio ICH. Pero sucedió que también en 1976 hubo que hacerlo, ante la petición que presentó un grupo de funcionarios de dicho organismo al Presidente de Gobierno, para que España votara en contra de Chile en la Asamblea General de las Naciones Unidas, en el debate sobre el estado de los derechos humanos. En su presentación, estos funcionarios acompañaron una lista de personas desaparecidas entre el 11 de septiembre de 1973 y agosto de 1976. "Se trataba de una campaña perfectamente orquestada por el Partido Comunista", dedujo el embajador (HINOJOSA, 2008, p. 242).

O motivo de Pinochet insistir em apropriar-se da cultura franquista é, segundo nossa hipótese, o desejo de separar-se da política cultural que o antecedeu: o folclorismo da Unidade Popular (UP). A proposta da UP propunha uma valorização das "origens americanas" e da cultura engajada, eternizada pelas músicas da Nueva Canción Chilena.

\section{O jogo político mais amplo}

Antes de analisar propriamente a reivindicação da hispanidade franquista pelo pinochetismo, julgamos necessário trazer algumas percepções mais amplas sobre o jornal $E l$ Mercurio $^{12}$ e a ditadura chilena. O periódico se destacou por apresentar justificativas para as políticas mais amplas do regime, como, por exemplo, aquelas relacionadas à aproximação com outras ditaduras do Cone $\operatorname{Sul}^{13}$. Analisamos a edição internacional do El Mercurio, publicada

12Tais informações foram retiradas do documentário, boicotado no Chile, El diario de Agustín (2008), nome dado pois o dono do jornal durante a ditadura de Pinochet era Agustín Edwards. O documentário é fruto de teses da Escuela de Periodismo da Universidad do Chile, e está disponível online: El Diario de Agustín. Direção de Ignacio Agüero. Santiago: Amazonía Films; Ignacio Agüero \& Associado, 2008. (80 min.), son., color. Legendado. Disponível em: <https://www.youtube.com/watch?v=6Hs60_o_Yv0\&t=40s>. Acesso em: 02 maio 2020.

13Embora a pesquisa foque na relação com Franco, gostaríamos de destacar que isso não elimina as relações com outras ditaduras do Cone Sul, o que propiciou a Operação Condor, por exemplo. Na página 7 da edição internacional da semana de 30 de dezembro de 1974 a 05 de janeiro de 1975, na mensagem de final de ano, o ditador chileno disse: "Asimismo, se retomaron los contactos internacionales con Brasil, Uruguay y Paraguay, casi anulados durante el régimen anterior. Con énfasis deseo destacar la inalterable confraternidad que nos une a todas las naciones hermanas de América, de cuyos gobiernos y pueblos hemos encontrado siempre expresiones de apoyo y comprensión, gestos que nosotros retribuimos con igual afecto." 
semanalmente, a qual destacava alguns discursos de Pinochet no delicado jogo político com a opinião pública internacional. Ao longo das leituras do jornal é notável o seu caráter de defensor do regime ditatorial de Pinochet, com a divulgação dos discursos do ditador em diversas ocasiões. Para esta seção do artigo, buscamos não apenas textos relacionados ao funeral de Franco e ao Dia da Hispanidade, ocasiões em que a apropriação fica mais evidente, mas também uma percepção geral da materialidade do periódico.

Notamos que Pinochet pensava a construção de uma América Hispânica não apenas em relação à "pátria mãe", Espanha, mas também com "as nações irmãs" da América, o que complementa o discurso de América Hispânica. A partir disso, podemos refletir que o pensamento conservador, e mais especificamente os regimes autoritários de direita, também pensam em formas de americanismos.

Considerando americanismo como identidades e vinculações (políticas, culturais) entre países latino-americanos, podemos interpretar a própria Operação Condor como um americanismo autoritário, ditatorial e violento. Não apenas pela operação em si, mas pelas proximidades e continuidades entre os países citados - Chile, Brasil, Uruguai, Paraguai e Argentina -, onde o elemento principal para esse americanismo autoritário é a Doutrina de Segurança Nacional, à medida que é o fator comum que permite a criação de um procedimento jurídico internacional de perseguição política, tortura e morte. É nesse sentido, mas especificamente no plano cultural, que buscamos analisar as conexões transatlânticas que o pinochetismo buscou no franquismo.

\section{O jogo de espelhos}

O jogo de espelhos entre Francisco Franco e Augusto Pinochet, para além das apropriações culturais que o pinochetismo fez do franquismo, está também nas desconcertantes semelhanças entre os dois regimes.

Francisco Franco, general espanhol, após a Guerra Civil espanhola (1936-1939) assumiu como chefe do poder Executivo de "uma Monarquia sem rei" (TUSELL, 2005) permanecendo nesse posto até 1973, quando foi afastado por motivos de saúde. Contudo, manteve-se na posição de chefe do Exército até sua morte, em 1975. De forma semelhante, 
Augusto Pinochet, general chileno, assumiu depois de um violento golpe de Estado, ficando no poder de 1973 até 1990, após a vitória do "No" por ocasião do plebiscito de 1988. No entanto, à semelhança de Franco, manteve-se como comandante do exército até 1998 e como senador vitalício até $2002^{14}$, tendo falecido em 2006 (HUNEEUS, 2007).

Já no que diz respeito ao funeral de Francisco Franco, trata-se de um evento que foi alvo de muitas divulgações dentro do país. Um exemplo importante foi a divulgação de um encarte com 88 fotografias do enterro de Franco no Valle de Los Caídos ${ }^{15}$, produzido pelo jornal espanhol ABC.

No entanto, o funeral de Franco teve pouca repercussão fora da Espanha, razão que explica a escassa presença de lideranças internacionais. Além de Pinochet, estiveram lá: o rei Hussein, da Jordânia; o príncipe Rainier III, de Mônaco; Imelda de Marcos, esposa do ditador filipino Ferdinand Marcos; e Nelson Rockefeller, vice-presidente dos Estados Unidos na presidência de Gerald Ford (1974-1977) ${ }^{16}$.

Durante sua visita diplomática, Pinochet fez discursos não apenas homenageando e exaltando a memória de Franco, como também criticando o rei Juan Carlos I, que não mencionara o ditador espanhol em seu discurso de posse, ocorrido entre a morte e o funeral, em 22 de novembro de 1975. A motivação para tal crítica é menos por Franco e mais por si mesmo, afinal Pinochet não foi convidado para a cerimônia, bem como a ascensão de Juan Carlos I marcou o distanciamento entre Chile pinochetista e Espanha em redemocratização, conforme explicado anteriormente. Nessa cerimônia, de acordo com Hinojosa, Pinochet fez o seguinte comentário:

\footnotetext{
De la ceremonia en el Palacio de las Cortes guardo un sentimiento de dolor, pues cuando habló S. M. el Rey Juan Carlos I no tuvo ni una frase de reconocimiento para el Generalísimo Franco ni para la familia de éste. Fue un gesto de ingratitud que no se aviene con la hidalguía española (HINOJOSA, 2008, p. 240, apud PINOCHET, 1991, p. 104).
}

14Evidentemente a renúncia dos cargos em 1998 e 2002 não foi por desapego ao poder. Ocorreu em consequência de sua prisão, em Londres, entre 1998 e 2000. E, ironicamente, a ordem de prisão foi emitida por um juiz da Espanha, já redemocratizada (STERN, 2009).

$15 \mathrm{O}$ Valle de Los Caídos é um monumento aos mortos da Guerra Civil Espanhola, construído por Franco para consolidação da memória nacionalista - Primo de Rivera, fundador da Falange, também foi enterrado no local. 16Informações obtidas a partir da análise dos jornais da ABC entre os dias 20 e 25 de novembro de 1975, ou seja, entre o dia da morte de Franco e o dia seguinte ao seu funeral, realizado em 24 de novembro. 
Importante destacar que analisamos a versão impressa do discurso de Pinochet, já que são feitas edições pelos jornais que buscam dar ênfase em determinados aspectos. Conforme explica Tânia de Luca, ao analisarmos jornais e revistas lidamos com o que se tornou notícia, o que implica atentar-se às motivações em destacar alguns acontecimentos no lugar de outros (LUCA, 2008, p. 140). Tais motivações relacionam-se ao posicionamento político dos jornais El Mercurio e $A B C$ defensores, respectivamente, do pinochetismo e do franquismo. No caso do discurso de Pinochet citado por Hinojosa, a motivação é mais explícita, afinal trata-se de um discurso reproduzido no livro do próprio Pinochet.

No entanto, como tais discursos já foram abordados em outros trabalhos ${ }^{17}$, o que buscamos realizar foi uma investigação sobre a apropriação da hispanidade franquista pela chilenidade pinochetista para além dos discursos de Pinochet, sobretudo os feitos durante o funeral de Franco. Isso porque discursos durante uma visita diplomática não indicam exatamente uma apropriação cultural, mas talvez apenas um elogio político. Também buscamos uma compreensão dessa apropriação cultural para além da retórica do "combate ao comunismo", afinal tal apelo é um senso comum de tiranos até os dias de hoje, utilizado como uma resposta simplista e rápida, mas que também é aglutinadora dentro do pensamento conservador.

Diante disso, encontramos tais apropriações culturais no âmbito das celebrações do Dia da Hispanidade ou Festa da Raça, celebração que ocorre no dia 12 de outubro em comemoração ao aniversário da chegada de Cristóvão Colombo na América, em $1492^{18}$. Como já apontamos, Colombo era, juntamente à Isabel de Castela, um símbolo da Espanha Imperial muito utilizado pela retórica da hispanidade (ZORRILLA, 2014, p. 182). Uma prova desse uso foi a primeira celebração do Dia da Hispanidade no regime franquista, ocorrida em 1939, apenas alguns meses após o fim da Guerra Civil (MARCILHACY, 2017, p. 87).

17Refiro-me, sobretudo, a quatro: a tese de Héctor Gustavo Opazo Romero; o volume dois sobre história da transição democrática na Espanha organizado por Álvaro Soto; e os dois trabalhos de Isabel Jara Hinojosa já mencionados.

18Tal festa também ocorre nos Estados Unidos como “Columbus Day”. 
Na celebração realizada em 12 de outubro de 1975, em Santiago do Chile, o jornal El Mercurio trouxe uma reportagem, sobre a qual destaco as falas do pesquisador e professor Eugenio Pereira Salas ${ }^{19}$ :

El presidente de la Academia Chilena de la Historia del Instituto de Chile, Eugenio Pereira Salas, investigador, profesor y autor de varias obras especialmente de la colonia y de la independencia:

"El 12 de octubre, Fiesta de la Raza o de la Hispanidad es algo más que un día de fiesta de una efeméride gloriosa que celebra toda la comunidad americana. Simboliza la incorporación a la historia universal de un Nuevo Mundo, de una civilización americana basada en los conceptos religiosos y transcendentes del cristianismo, en las heroicas tradiciones españolas y en los conceptos vernaculos y originales de las culturas del continente [destaque nosso].

Nesse pronunciamento vemos a repetição - em outros termos - da hispanidade difundida pelos Cuadernos Hispanoamericanos. Em ambos os discursos tais conceitos são recuperados enquanto singulares coletivos ${ }^{20}$ (KOSELLECK, 2013) que, vindos da nobre nação espanhola, adiantaram o Chile na história. O discurso de Salas enfatiza uma história universal na qual o Novo Mundo foi incorporado graças à generosidade espanhola e, claro, à religião católica. Eugenio Pereira Salas, visto como um dos intelectuais fundadores do folclorismo no Chile (GARCIA, 2009, p. 13) cumpriu nesse discurso o papel de justificar a hispanidade como elemento para chilenidade pinochetista, através do lugar de poder à parte que ocupava enquanto intelectual e acadêmico ${ }^{21}$.

19Eugenio Pereira Salas (1904-1979) foi um historiador chileno, com especial interesse nos estudos culturais. Professor da Universidade do Chile, presidiu o Instituto de Investigações Musicais. Os estudos sobre ele focam no seu papel na fundação dos estudos acadêmicos do folclorismo chileno. Ver: Biblioteca Nacional de Chile. Eugenio Pereira Salas (1904-1979). Memoria Chilena. Disponível em: http://www.memoriachilena.gob.cl/602/w3-article618.html\#. Acesso em 18 de abril de 2020; e também o artigo de Tânia da Costa Garcia (2009).

20A ideia foi utilizada por Koselleck para explicar o conceito de história moderno, aliado ao nacionalismo e ao imperialismo, que buscou impor uma visão eurocêntrica como universal e unívoca. Aqui utilizamos a ideia de singular coletivo para compreender a justificativa universal dada a hispanidade, tanto no franquismo como no pinochetismo.

21 "Na historiografia dos atores do político, os intelectuais ocupam indiscutivelmente um lugar à parte." (SIRINELLI, 2003. p. 233). 


\section{Hispanidade e Chilenidade}

No esforço de compreender os elementos de apropriações e os jogos entre Franco e Pinochet, queremos destacar dois pontos. O primeiro diz respeito aos valores da hispanidade língua e cultura espanhola - resgatados durante o pinochetismo por meio do Dia da Hispanidade, em oposição ao que fora feito pela Unidade Popular (UP) ao fortalecer o folclore e propor uma "nova cultura" para um "homem novo". Contrariamente à proposta da Via chilena ao socialismo, o pinochetismo propõe a "velha cultura" e o "homem velho" da "pátria mãe" para compor a chilenidade.

Já o segundo ponto trata da reflexão em torno das semelhanças entre as concepções de América Latina para Pinochet e para Franco. Dentro disso está incluso pensar a ideia de unidade política contra insurgentes e ameaças do "internacionalismo" representado por socialistas e comunistas, tanto na Unidade Popular como na Segunda República Espanhola. Em ambos os casos, uma noção de "sacrifício" foi invocada para vencer os inimigos da nação, reconhecimento implícito de que os governos foram autoritários e não consideravam a democracia como um valor a ser respeitado - a UP e os governos da Segunda República Espanhola foram eleitos democraticamente. Assim, consideramos que a decisão cultural do pinochetismo em voltar a práticas culturais passadas representa uma abrupta ruptura com a política cultural do governo anterior, paralelamente à reviravolta social, política e econômica.

Diante disso, a presença das revistas culturais expressam a circulação de um ideário cultural entre grupos letrados e formadores de opinião. Como observa Regina Crespo, as revistas culturais ou intelectuais eram um espaço privilegiado para debates do campo social e político, o que respalda nossas ideias já que entendemos que os debates sociopolíticos nascem de discussões culturais e intelectuais - diferente de dizer que são criadas e geradas exclusivamente pela figura do intelectual ${ }^{22}$.

Já em relação ao IchCH, como se viu, o instituto fora criado em Santiago, em 1948, como uma filial do ICH. A criação foi efetuada por um grupo católico corporativista que integrava a

22A noção de intelectual como um corpo unido que pensa coletivamente a melhoria social e política é um produto da modernidade (FUNES, 2006, p. 39). 
revista Estudios, sendo liderado pelo historiador Jaime Eyzaguirre, os filósofos Osvaldo Lira e Julio Philippi e o escritor Roque Esteban Scarpa (HINOJOSA, 2008). Segundo a autora, pensavam um projeto a longo prazo - razão pela qual fundaram um instituto cultural hispânico, em vez de um partido franquista. Já em relação ao legado do IchCH em 1973, a historiadora chilena coloca:

Así pues, un "constructo" ideológico de primera hora de la dictadura española, renovado después con las teorías jurídicas tardofranquistas, se proyectó en la legitimación ideológico-cultural de la dictadura chilena casi cuarenta años después. La 'Hispanidad' pudo mantenerse como uno de los sustratos ideológicos de la derecha y reaparecer en gloria y majestad después del golpe militar, al punto que la Declaración de Principios de la Junta de Gobierno Militar de Chile (1974), rechazó la solución marxista, entre otras razones, porque contradecía "nuestra tradición cristiana e hispánica" (HINOJOSA, 2008, p. 234).

Logo, a parte final da citação acima já reforça nosso argumento de que o resgate da hispanidade passa pelo critério de estabelecer não apenas um marco divisório, mas uma cordilheira com a Unidade Popular. Isso porque a experiência socialista da UP não apenas buscava uma "nova cultura" para o "homem novo" do socialismo chileno, mas também, ao fazer isso por meio do resgate cultural em torno do folclore, propunha também um outro americanismo. Para Schmiedecke:

Seguindo o exemplo do Quilapayún, grupos como Inti-Illimani, Curacas, Illapu e Aparcoa centraram seu repertório no folclore indígena com vistas a "resgatar os valores culturais de nosso povo". Nessa busca, os músicos recusaram as fronteiras geográficas que separavam o Chile dos demais países latino-americanos, pois entendiam que elas não corresponderiam aos contornos culturais. Como expressou Osvaldo Rodríguez em uma análise posterior, "[...] o que se levantava naqueles anos no Chile não era um problema acerca da música chilena senão da música latinoamericana como expressão comum". Segundo essa perspectiva, haveria uma identidade cultural que conectaria as diferentes expressões musicais da região, portanto, não caberia buscar elementos exclusivos da música chilena, mas antes evidenciar seu pertencimento a uma tradição continental (SCHMIEDECKE, 2017, p. 168).

A chilenidade pinochetista não se embasava somente nas construções espanholas, mas também nas apropriações da hispanidade feitas no Chile. Contudo, tais apropriações não ocorreram apenas através do IchCH. Um exemplo é a construção da chilenidade a partir da criação do mito de herói nacional em torno de Diego Portales no início do século XX, bem como 
seus resgates posteriores (CAPELATO, 2014). Principalmente nas décadas de 1920 e 1930, com o desejo de construção de uma identidade autenticamente chilena, e após o golpe de 1973, com o intuito de reforçar uma identidade que justificasse o golpe.

Ao pensarmos as semelhanças entre os projetos de Franco e Pinochet para a América Latina, notamos que ambos estão debatendo, ou mais exatamente, tentando responder a formulações e críticas feitas pela esquerda. Pinochet resgatou a hispanidade para elaborar uma chilenidade diametralmente oposta àquela preconizada pela UP, através do IchCH e do Dia da Hispanidade. Nesse mesmo sentido, pelo lado franquista, o surgimento dos Cuadernos Hispanoamericanos em 1948 se deu como resposta aos Cuadernos Americanos, fundados em 1942, conforme já explicado. Mas tal oposição torna-se ainda mais escancarada se consideramos o contexto em que as revistas intelectuais surgem, conforme explica Regina Crespo:

\footnotetext{
No se puede ignorar que estas revistas vinieron a la luz en el contexto marcado por el fin de la Primera Guerra Mundial, la desilusión ante el fallido modelo político y social europeo y las expectativas de transformación generadas por la Revolución rusa. Sin embargo, más allá de esa situación, surgieron como un intento de responder a inquietudes, por decirlo de alguna manera, regionales, a las que si podían encontrar alternativas propias que señalaran nuevos caminos para el continente (CRESPO, 2010, p. 18).
}

A relação entre a criação das revistas no mundo e seu fortalecimento na América Latina com projetos culturais e políticos da esquerda revolucionária reforça o argumento de que a criação desses recursos intelectuais dentro de regimes autoritários de extrema-direita foi forjada enquanto tentativa de resposta.

Por fim, é importante comentar uma inflexão que notamos. Em todas as fontes analisamos também um ano antes e um ano depois do recorte proposto, para buscar continuidades e/ou rupturas. No jornal El Mercurio, sobre o Dia da Hispanidade, percebemos uma inflexão a partir do ano seguinte. Em 1976, o Rei Juan Carlos I de Espanha fez uma viagem por vários países da América, por ocasião do Dia da Hispanidade, e há evidências de que o simbolismo dessa data comemorativa sofreu alterações com a redemocratização espanhola. 


\section{Considerações finais}

O objetivo da pesquisa foi apresentar diferentes estratos de tempo e regimes de historicidade, desde a reconfiguração do hispanismo em hispanidade, até a apropriação dessa última para uma chilenidade pinochetista, que buscou uma ideia de nação que ignorasse a existência de um povo. Hispanidade e chilenidade utilizaram o legado colonial hispânico como forma de negar o presente. De qualquer forma, uma primeira leitura sobre tais apropriações culturais e ideológicas pode parecer uma história de ideias e projetos políticos que fracassaram. Infelizmente não é o caso.

A Espanha atual vivencia a presença do neofranquismo, inclusive com a peregrinação de partidários ao Valle de Los Caídos, onde, além de Franco, também foi enterrado Primo de Rivera. Em 2018, o presidente espanhol pelo Partido Socialista, Pedro Sánchez, propôs exumar os restos mortais de Franco de tal monumento, o que foi consolidado em 24 de outubro de 2019 (GALOCHA, 2020). Todavia, no mês seguinte daquele ano, o partido de extrema-direita espanhol Vox emergiu como terceira força política do país, valendo-se de símbolos e discursos do franquismo (CAPARRÓS, 2019).

No Chile, a Constituição de 1980, ainda vigente no país, foi elaborada por Jaime Guzmán, que, como explicamos, foi um admirador de Osvaldo Lira, precursor do IchCH nos anos 1940. A disputa cultural entre Pinochet e UP, no seu tempo e nos seus usos do passado, encontra hoje repercussões. Durante o estallido social no Chile, a partir de outubro de 2019, foi contestado o legado pinochetista, como as reformas neoliberais e a Constituição de 1980. Ao passo que a bandeira do povo indígena Mapuche teve lugar central nas manifestações, como na emblemática foto na ex-Praça Itália, atual Praça da Dignidade, em Santiago.

Um dos principais resultados dessas manifestações foi justamente um plebiscito para decidir se haveria uma Assembleia Constituinte, buscando superar a Constituição pinochetista. O plebiscito, marcado inicialmente para 26 de abril de 2020, foi adiado, por conta da pandemia de Covid-19, para 25 de outubro. O "aprovo" venceu com 78\% dos votos, ficando também decidido que haverá a eleição de uma Assembleia exclusiva para a elaboração da Constituição, em 2021, com paridade entre homens e mulheres. 


\section{Referências Bibliográficas}

\section{Fontes}

Cuadernos Hispanoamericanos: $\mathrm{n}^{\circ} 1$ (1948), $\mathrm{n}^{\circ} 2$ (1948), $\mathrm{n}^{\circ} 9$ (maio e junho de 1949), $\mathrm{n}^{\circ} 17$ (setembro e outubro de 1950), $\mathrm{n}^{\circ} 24$ (novembro e dezembro de 1951); $\mathrm{n}^{\circ} 28$ (abril de 1952); $\mathrm{n}^{\circ}$ 41 (maio de 1953); $\mathrm{n}^{\circ} 55$ (julho de 1954); $\mathrm{n}^{\circ} 70$ (outubro de 1955). Disponível em: http://www.cervantesvirtual.com/obra/cuadernos-hispanoamericanos-80/.

Edições do jornal $A B C$ dos dias 20, 21, 22, 23, 24 e 25/11/1975. Disponível em http://hemeroteca.abc.es/.

Edição internacional do jornal El Mercurio referente às semanas 30/12/1974 a 05/01/1975, 20 a 26/01/1975, 21 a 27/04/2975, 07 a 13/07/1975, 12 a 19/10/1975, 17 a 23/11/1975, 24 a 30/11/1975 e 07 a 14/12/1975. Consultados fisicamente no Instituto Ibero-Americano de Berlim.

\section{Bibliografia}

BEIRED, José Luis Bendicho. Hispanismo: um ideário em circulação entre a Península Ibérica e as Américas. In: VII Encontro Internacional da ANPHLAC, 2007, Campinas. Anais do VII Encontro Internacional da ANPHLAC, 2006. p. 1-9. Disponível em: $<$ http://anphlac.fflch.usp.br/sites/anphlac.fflch.usp.br/files/jose_beired.pdf $>$. Acesso em: 03 abr. 2020.

CAPARRÓS, Martín. Vox y los restos de Franco. 2019. The New York Times. Disponível em: https://www.nytimes.com/es/2019/11/14/espanol/opinion/vox-espana.html. Acesso em: 27 ago. 2020.

CAPELATO, Maria Helena R. O "ser chileno" em questão: identidade nacional e política. Territórios e Fronteiras. v.7, p.90-104, 2014.

CRESPO, Regina (org.). Revistas en América Latina: proyectos literarios, políticos y culturales. Cidade do México: UNAM e Ed. Eón, 2010.

CUEVAS, Pedro Carlos González. Maeztu: Biografía de un nacionalista español. Madrid: Marcial Pons, Ediciones de História, 2003.

DIFFIE, Bailey W. The Ideology of Hispanidad. Hispanic American Historical Review, [S.L.], v. 23, n. 3, p. 457-482, 1 ago. 1943. Duke University Press. http://dx.doi.org/10.1215/00182168-23.3.457. Disponível em: https://read.dukeupress.edu/hahr/article/23/3/457/154662/The-Ideology-of-Hispanidad. Acesso em: 19 ago. 2020. 
FINCHELSTEIN, Federico. A Brief History of Fascist Lies. Berkeley: University Of California Press, 2020.

FUNES, Patricia. Salvar la nación: Intelectuales, cultura y política en los años veinte latinoamericanos. Buenos Aires: Prometeo Libros, 2006.

GALOCHA, Artur. La exhumación de Franco, paso a paso. 2019. El País. Disponível em: https://elpais.com/elpais/2019/10/21/media/1571679058_681727.html. Acesso em: 13 abr. 2020.

GARCIA, Tânia da Costa. Canción popular, nacionalismo, consumo y política en Chile entre los años 40 y 60. Revista Musical Chilena, Santiago, v. 63, n. 212, p. 11-28, jul./dez. 2009. Disponível em: https://scielo.conicyt.cl/scielo.php?script=sci_arttext\&pid=S071627902009000200003. Acesso em: 16 mar. 2020.

GRECCO, Gabriela de Lima. De la pluma como ofício a la pluma oficial: estado y literatura durante los nuevos estados de Getúlio Vargas y Francisco Franco (1936-1945). 2017. 591 f. Tese (Doutorado) - Curso de Faculdade de Filosofia e Letras, História Contemporânea, Universidad Autônoma de Madrid, Madrid, 2017. Disponível em: https://repositorio.uam.es/handle/10486/680035?fbclid=IwAR1KfYh-XNu-

STFg3gzeWJ95BpzA-u5WU2zpnzdV7i7D-HASvQathPRYd2c. Acesso em: 17 ago. 2020.

La pluma azul en la república andina: samuel ros, un escritor falangista exiliado en chile (1937-1938). Historia 396, Valparaíso, v. 9, n. 1, p. 41-71, out. 2019. Instituto de Historia PUCV-Chile. Disponível em: http://www.historia396.cl/index.php/historia396/article/view/340. Acesso em: 25 ago. 2020.

HARTOG, François; REVEL, Jacques (org.). Les usages politques du passé. Paris: École Des Hautes Études En Sciences Sociales, 2001.

HINOJOSA, Isabel Jara. De Franco a Pinochet: el proyecto cultural franquista en Chile, 19361980. Santiago: Lom Ediciones, 2006.

La ideología franquista en la legitimación de la dictadura militar chilena.

Revista Complutense de História da América, Madrid, v. 34, n. 1, p.233-253, jan. 2008.

HUNEEUS, Carlos. The Pinochet regime. Boulder, CO: Lynne Rienner Publishers, 2007.

KOSELLECK, Reinhart. O conceito de História. Belo Horizonte: Autêntica Editora, 2013.

LEVI, Giovanni. Le passé lointain, sur l'usage politique de l'histoire. In: HARTOG, François;

REVEL, Jacques (org.). Les usages politiques du passé. Paris: École Des Hautes Études En 
Sciences Sociales, 2001.

LUCA, Tania Regina de. História dos, nos e por meio dos periódicos. In: PINSKY, Carla Bassanezi (org.). Fontes Históricas. São Paulo: Contexto, 2008. p. 111 - 153.

MARCILHACY, David. La Hispanidad bajo el franquismo: el americanismo al servicio de un proyecto nacionalista. In: MICHONNEAU, Stéphane; NÚÑEZ-SEIXAS, Xosé M. Imaginarios y representaciones de España durante el franquismo. Madrid: Casa de Velázquez, 2017. p. 73102. Disponível em: https://books.openedition.org/cvz/1161. Acesso em: 18 ago. 2020.

MARTÍNEZ, Luis Velasco (org.). Falangistas y franquistas en América (1936-1975): un estado de la cuestión. Historia 396, Valparaíso, v. 9, n. 1, p. 1-18, out. 2019. Instituto de Historia PUCV-Chile. Disponível em: http://www.historia396.cl/index.php/historia396/article/view/338. Acesso em: 25 ago. 2020.

MARTINS, Maria Antonia Dias. A Identidade Ibero-americana em revista: Cuadernos Americanos e Cuadernos Hispanoamericanos, 1942-1955. Tese apresentada à Faculdade de Filosofia, Letras e Ciências Humanas da Universidade de São Paulo para obtenção do título de Doutora em História Social. 2012.

MOYN, Samuel; SARTORY, Andrew. Global Intellectual History. Nova Iorque: Columbia University Press, 2013.

MYERS, Jorge. Músicas distantes. Algumas notas sobre a história intelectual hoje: horizontes velhos e novos, perspectivas que se abrem. In: SÁ, Maria Elisa Noronha de (org.). História intelectual latino-americana: itinerários, debates e perspectivas. Rio de Janeiro: Ed. PUC-Rio, 2016, p. 23.

REIS, Mateus Fávaro. Exílio, memórias e testemunho: para ler 'Visto y vivido en Chile', de Luis Alberto Sánchez. In: XXVII Simpósio Nacional de História, 2013. Natal: Anais eletrônicos, 2013.

RODRÍGUEZ-MARTÍNEZ, Ruth; TULLOCH, Christopher; LLOVERAS, Jaume Guillamet. Franquismo, monarquía y democracia. La posición política de los principales diarios (ABC, La Vanguardia Española, Informaciones y YA) durante la transición española a la democracia (1975-1977). Estudios Sobre El Mensaje Periodístico, [s.1.], v. 23, n. 1, p. 603-614, 11 jul. 2017. Universidad Complutense de Madrid (UCM). http://dx.doi.org/10.5209/esmp.55616. Disponível em: https://revistas.ucm.es/index.php/ESMP/article/view/55616. Acesso em: 06 jun. 2020.

ROMERO, Héctor Gustavo Opazo. Los actores no gubernamentales españoles ante el régimen militar de Augusto Pinochet (1973-1990): apoyo a la democratización y defensa de los derechos humanos. 2009. 489 f. Tese (Doutorado) - Curso de Relaciones Internacionales, Departamento de Derecho Internacional Público y Relaciones Internacionales, Universidad Complutense de Madrid, Madrid, 2009. 
RONIGER, Luis; KIERSZENBAUM, Leandro. Los intelectuales y los discursos de derechos humanos: La experiencia del Cono Sur. Estudios Interdisciplinarios de América Latina. Tel Aviv, p. 5-36. jun. 2005.2 Disponível em: http://eial.tau.ac.il/index.php/eial/article/view/348/317. Acesso em: 27 maio 2020.

SCHMIEDECKE, Natália Ayo. "Nuestra mejor contribución la hacemos cantando": a Nova Canção Chilena e a "questão cultural" no Chile da Unidade Popular. Franca: [s.n.], 2017. 270 f. Tese (Doutorado em História). Universidade Estadua Paulista. Faculdade de Ciências Humanas e Sociais. Orientadora: Tânia da Costa Garcia.

SIRINELLI, Jean-François. Os intelectuais. RÉMOND, René (org.). Por uma história política. Tradução: Dora Rocha. 2 ed. Rio de Janeiro: Editora FGV, 2003. p. 231 - 269.

SOTO, Álvaro e outros (org.). Historia de la transición y consolidación democrática en España, Vol 2. Madrid: Universidad Autónoma de Madrid, 1995.

STERN, Steve J. Recordando el Chile de Pinochet: en vísperas de Londres, 1998. Santiago: Ediciones Universidad Diego Portales, 2009.

TUSELL, Javier. Dictadura franquista y democracia, 1939-2004. Barcelona: Crítica, 2005.

VÁSQUEZ, Sergio Andrés Aedo. España y Chile: articulación de una Historia antidemocrática en el siglo XX. Refundación de las bases del estado nacional durante el franquismo y el pinochetismo. 2015. 489 f. Tese (Doutorado) - Curso de História, Universidad de Extremadura., Cáceres, 2015. Disponível em: 〈http://dehesa.unex.es/handle/10662/3901>

ZORRILLA, Elena Maza. El mito de Isabel de Castilla como elemento de legitimidad política en el franquismo. Historia y Política, Madrid, v. 1, n. 31, p. 167-192, 30 jul. 2014. Semestral. Disponível em: https://recyt.fecyt.es/index.php/Hyp/article/view/21542. Acesso em: 22 ago. 2020. 